\title{
Anti-angiogenesis: making the tumor vulnerable to the immune system
}

\author{
Arjan W. Griffioen
}

Received: 11 January 2008 / Accepted: 14 April 2008 / Published online: 26 April 2008

(C) The Author(s) 2008

\begin{abstract}
Ongoing angiogenesis has been shown to possess immune suppressive activity through several mechanisms. One of these mechanisms is the suppression of adhesion receptors, such as intercellular adhesion molecule-1, vascular cell adhesion molecule-1 and E-selectinadhesion molecules involved in leukocyte interactions-on the vascular endothelium. This phenomenon, when happening to the tumor endothelium, supports tumor growth due to escape from immunity. Since angiogenesis has this immune suppressive effect, it has been hypothesized that inhibition of angiogenesis may circumvent this problem. In vitro and in vivo data now show that several angiogenesis inhibitors are able to normalize endothelial adhesion molecule expression in tumor blood vessels, restore leukocyte vessel wall interactions, and enhance the inflammatory infiltrate in tumors. It is suggested that such angiogenesis inhibitors can make tumors more vulnerable for the immune system and may therefore be applied to facilitate immunotherapy approaches for the treatment of cancer.
\end{abstract}

Keywords Angiogenesis - Immunotherapy · Adhesion molecules

This article is a symposium paper from the conference "The European Society for Medical Oncology (ESMO) and the European Society for Cancer Immunology and Immunotherapy (ESCII) International Symposium on Immunology", held in Athens, Greece, on 15-17 November 2007.

A. W. Griffioen $(\bowtie)$

Angiogenesis Laboratory, Department of Pathology, Research Institute for Growth and Development (GROW), University Hospital Maastricht, PO Box 5800,

6202 AZ Maastricht, The Netherlands

e-mail: aw.griffioen@path.unimaas.nl

URL: http://www.angiogenesis.nl

\section{Introduction}

Immune cells are circulating and recirculating cells, hunting for antigens that are non-self thereby trying to get rid of agents such as non-self molecules, microorganisms, (virally) infected host cells, and otherwise altered host cells. Tumor cells are genetically mutated cells that can be recognized and eliminated by the immune system. This recognition and elimination is apparently an extremely efficient process, given that facts that (1) in an average person 70,000 billion cells are continuously exposed to multiple mutating environmental factors, such as carcinogens in food, fine dust, sunlight, and (cosmic) radiation, (2) it has been estimated that on average 10,000 DNA repair activities are necessary in each cell every day, and (3) that cancer only develops in a minority of people.

Despite the efficiency of the immune system, cancer can develop due to mechanisms evolved by tumors to escape from surveillance of immune cells. These mechanisms are multiple and several of them have been discovered over the last decades. Tumor antigens may not be specific enough for discrimination from normal host cells. Tolerance may be induced by insufficient stimulation of co-stimulation of accessory molecules on lymphocytes. Tumors may downregulate MHC molecules to escape from (cytotoxic) $\mathrm{T}$ cell recognition. In addition, tumors may produce immune inhibitory molecules such as IL-10, TGF- $\beta$ or prostaglandins. Alternatively, activation of regulatory $\mathrm{T}$ cells that suppress the specific immunity may be too efficient. There is also another means of tumor escape from immunity which is based on changes in the tumor vasculature. Tumors are able to down regulate adhesion molecules on the vascular endothelium. These are not the adhesion molecules that are involved in the interaction with the extracellular matrix - these are often induced 
during angiogenesis-but the endothelial adhesion molecules that are necessary for interactions with leukocytes, such as granulocytes, macrophages, NK cells and lymphocytes. The suppression of these adhesion molecules, and thereby the adhesive properties of the endothelium, was found to be caused by exposure of endothelial cells to angiogenic growth factors produced by the tumor. Angiogenesis is required for the outgrowth of tumors, and plays a role in metastasis formation, and outgrowth as well [1-4]. Angiogenesis is intricately regulated by stimulators and inhibitors. In normal tissues angiogenesis is switched off, but in tumors the process is stimulated through production of cytokines such as vascular endothelial cell growth factors (VEGFs) and fibroblast growth factors (FGFs) by tumor cells. It has been known for long time that tumor blood vessels have suppressed expression of adhesion molecules [5-8]. Evidence has been building that tumor cells are involved in the efficient downregulation of these adhesion receptors, through the production of angiogenic growth factors, as is described in this review.

\section{Angiogenic growth factors make endothelial cells unresponsive to inflammatory signals-the discovery of tumor endothelial cell anergy}

In an effort to investigate ways to improve immunotherapy approaches for the treatment of cancer, it was found that endothelial cells isolated from human tumors express significantly lower levels of adhesion molecules that are involved in leukocyte-vessel wall interactions, such as intercellular adhesion molecule-1 (ICAM-1), vascular cell adhesion molecule-1 (VCAM-1), E-selectin and CD34. As this feature may provide tumors with an immuno-privileged status, it was investigated what the mechanism of this lack of adhesive properties of tumor endothelium was. It was found that the disappearance of these adhesion molecules is due to exposure to tumor derived angiogenic growth factors [9-12]. Since ICAM-1 is the most important adhesion molecule involved in the extravasation of leukocytes into the surrounding tissue-it has been demonstrated to be both required as well as sufficient for the process of extravasation-most studies have been focused on the expression of ICAM-1. In Fig. 1a the response of umbilical vein endothelial cells (HUVECs) to bFGF exposure is shown. Both bFGF and VEGF, which are the strongest mitogenic factors for endothelial cells, but also other growth factors, such as epidermal growth factor (EGF) and placental growth factor (PlGF) were found to be able to downregulate ICAM-1though to a lesser extent-on the surface of endothelial cells in vitro (Fig. 1b).

Not only were these adhesion molecules absent in tumor endothelial cells, it was also discovered that endothelial cells exposed to tumor derived growth factors are unresponsive to inflammatory cytokines such as interleukin-1, interferon-gamma, and tumor necrosis factor- $\alpha$. These inflammatory cytokines normally induce an adhesive phenotype in endothelium by induction of adhesion molecules, but angiogenic endothelial cells are refractory to these signals. The lack of leukocyte adhesion receptors and the unresponsiveness to inflammatory signals has been termed tumor endothelial cell anergy [9, 10]. This anergy ultimately results in abrogation of immune surveillance and escape of the tumor from immunity, allowing undisturbed outgrowth and metastasis formation.

Despite the growing body of research that describes suppression of adhesiveness of endothelial cells during angiogenesis, there are also reports describing that angiogenesis may also be involved in induction of adhesion molecules and leukocyte-vessel wall interactions. Melder et al. [12] described that VEGF has an opposite function as bFGF, stimulating expression of ICAM-1 and inducing adhesiveness. In another study VEGF transgenic mice were found to have an increased microvessel density and an enhanced
Fig. 1 Angiogenic stimulation of endothelial cells suppresses ICAM-1 expression. a Suppression of ICAM-1 on HUVEC after exposure to $10 \mathrm{ng} / \mathrm{ml}$ bFGF. Maximal induction of proliferation (3H-thymidine incorporation) approximately $100-120 \%$ at day 3 .

b Suppression of ICAM-1 expression in HUVEC by different growth factors, in a 3 day culture
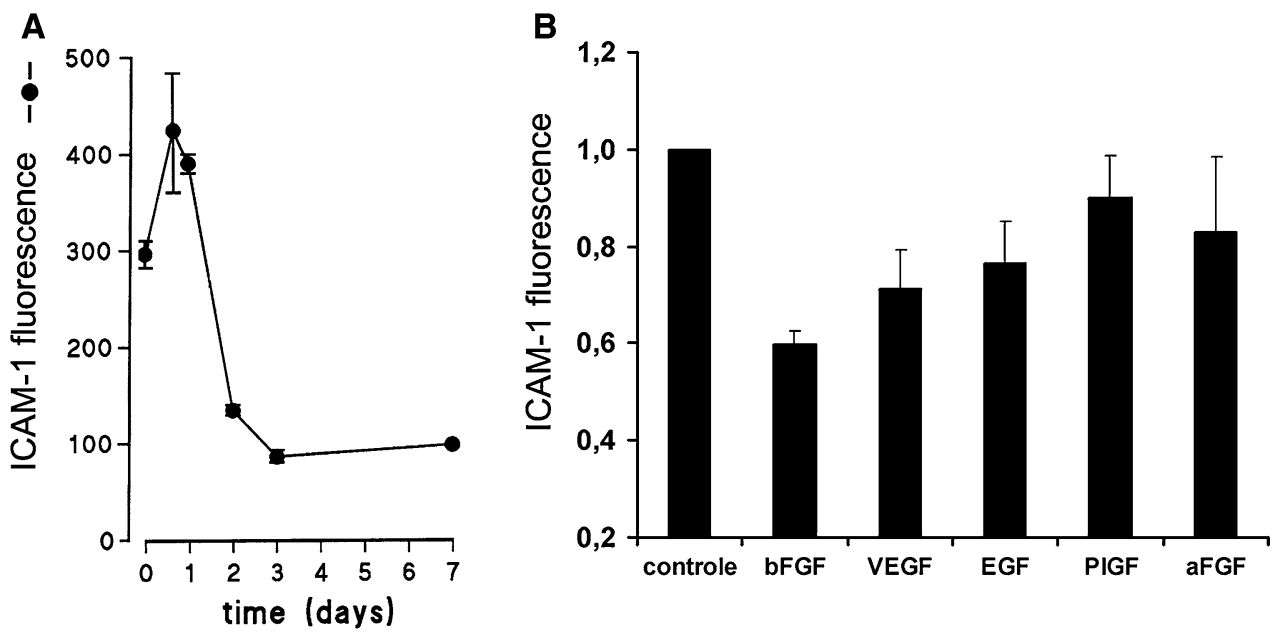
leukocyte rolling and adhesion in the skin [13]. This apparent discrepancy might have an explanation in the sequence of events. It is shown in Fig. 1a that endothelial cells exposed to mitogenic signals first upregulate ICAM- 1 after which a marked and prolonged suppression occurs. It is unknown why endothelial cells first upregulate the expression, but it may be related to the function of ICAM-1 as a receptor for extracellular matrix components, such as hyaluronic acid [14]. It is known that receptors for matrix interactions such as the integrins are induced during angiogenesis to prepare the cells for migration into the direction of the angiogenic stimulus. It is feasible that ICAM-1 has a dual function. Involvement in endothelial cell migration during early stages of cell activation, and suppression of leukocyte interaction during later stages. That the induction of ICAM-1 is not a commonality among angiogenic growth factors is suggested by the fact that other angiogenic growth factors are able to suppress this stimulatory activity of VEGF [15].

In my view an inverse relationship between angiogenesis and adhesiveness is the most logical scenario, also because of the general cell biology principle that a cell preparing for growth will de-differentiate and suppress other activities, while differentiation to an adhesive phenotype may be more logically associated with slower growth. The inverse relationship with angiogenesis and inflammatory processes was also observed in a study where inflammatory cytokines were found to inhibit the proliferation of endothelial cells. A key molecule in this process was found to be guanylate binding protein-1 $[16,17]$.

Several mechanisms have been shown to be involved in the downregulation of endothelial cell adhesion molecules. One of these was discovered in an effort to identify the epigenetic component in tumor angiogenesis [18]. By pharmacological inhibition of epigenetic regulatory mechanisms such as promoter hypermethylation and histone deacetylation, it was unexpectedly found that ICAM-1 was among the genes that were most efficiently re-induced [19, 20]. Indeed, the ICAM-1 gene contained $\mathrm{CpG}$ islands. These are CG-rich foci in the sequence that allow methylation of the promoter DNA, which may result in silencing of the gene. Interestingly, it was not the promoter methylation component, but rather the histone deacetylation related mechanism that was responsible for the absence of ICAM-1 in tumor endothelium [19].

Another mechanisms of angiogenic growth factor mediated induction of endothelial cell anergy was through the sustained activation of p38 MAPK and subsequent inhibition of the transcription factor NFkB, which is under normal conditions heavily involved in the upregulation of ICAM-1 [21]. The latter was only demonstrated for bFGF but the results are highly suggestive for a commonality among angiogenic growth factors for this activity.
Although these mechanisms do show some insight as to how EC anergy is regulated, they do not exclude other additional explanations.

\section{Ongoing angiogenesis prevents leukocyte-vessel wall interactions and leukocyte infiltration}

To investigate whether the angiogenesis mediated signals have the expected impact on the function of endothelial cells, in vitro leukocyte adhesion assays, and in vivo intravital microscopy studies were performed. These studies indicated that indeed exposure of endothelial cells to individual recombinant angiogenic growth factors reduce adherence of leukocytes under static conditions [9] and both rolling and firm adhesion under sheer stress conditions [22]. In vivo studies of implantation of slow-release pellets containing recombinant bFGF or VEGF showed that the mere exposure to these factors dramatically reduces adhesive properties of endothelial cells also after stimulation with TNF- $\alpha$ [23]. In several in vivo tumor models in mice it was shown that leukocyte rolling as well as firm adhesion to the vessel wall in the tumor vasculature is markedly reduced [12, 24] (Fig. 2). These studies were carried out in small tumors grown in the ears of athymic nude mice, in order to be able to perform intravital microscopy in a non-invasive way. This technique allowed us to demonstrate that also blood vessels outside but close to the tumor, are under regulation of tumor-derived angiogenic growth factors. It was even demonstrated that leukocytevessel wall interactions in general are hampered systemically in mice carrying a large tumor on the flank [24]. It is tempting to speculate that the latter result may account for the known impairment of immune functions in patients with cancer.

The thus developed theme of the relationship between angiogenesis and the immune system was further substantiated in human tumors. The first question that arose was whether there would be an angiogenesis based explanation for the difference between breast cancer patients with ductal carcinoma and with medullary carcinoma. The latter group of patients, which is a rather small group with a slightly better prognosis, is characterized by tumors with increased amounts of infiltrated leukocytes in the tumor, when compared to tumors of patients with ductal carcinomas. We found indeed a more pronounced profile of angiogenic factors in ductal carcinomas. By real-time PCR assessment, VEGF-A, bFGF, PIGF, and angiopoietins- $1,-2$, and -4 were all more strongly expressed by factor of 5-20. Interestingly, the largest differences were present in the expression levels of VEGF-C and -D, with a higher expression (200250 times) in ductal carcinomas. It was shown that both VEGF-C and -D can synergize with other angiogenic 

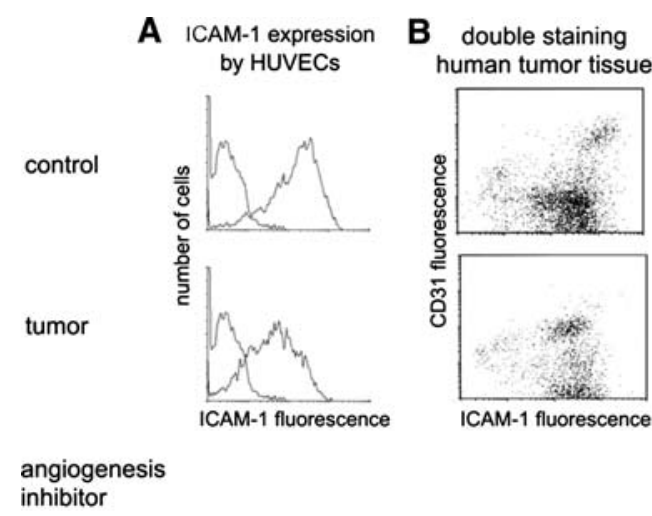

inhibitor

Fig. 2 Induction of ICAM-1 leads to leukocyte-vessel wall interactions and tumor infiltration. a Suppression of ICAM-1 on HUVEC after incubation in $10 \mathrm{ng} / \mathrm{ml}$ bFGF. b Expression of ICAM-1 on freshly isolated endothelial cells (CD31 double staining) from normal human renal tissue (upper panel) renal cell carcinoma tissue (lower panel). c Video stills of leukocyte-vessel wall interactions in normal tissue (upper panel), B16F10 mouse melanoma tumor tissue (middle panel)

growth factors such as bFGF, to downregulate ICAM-1 [25]. Also in tumor tissues of patients with colorectal carcinoma a negative correlation was found between expression of VEGF or the number of proliferating endothelial cells as measure of ongoing angiogenesis and leukocyte infiltration [26]. Kaplan-Meier analysis suggests that prognosis can seriously improve when based on both angiogenesis and leukocyte infiltration. A similar relationship was found by others in ovarian carcinoma. Zhang et al. [27] found that the number of infiltrated $T$ cells is a prognostic value predicting longer survival. In the same study it was found that this parameter was inversely correlated to the expression of VEGF.

\section{Inhibition of angiogenesis restores adhesiveness of tumor endothelium and leukocyte infiltration in tumors}

The immune-suppressive effects of ongoing angiogenesis made us hypothesize those inhibitors of angiogenesis may revert endothelial cell anergy and increase leukocyte infiltration in tumors, thereby enhancing the vulnerability of tumors to the immune system. It was found that a broad array of angiogenesis inhibitors-among which endostatin, anginex, anti-VEGF antibodies as well as chemotherapeutic compounds with claimed angiostatic activity-have the capacity to normalize the expression of adhesion molecules on tumor endothelial cells, as well as to normalize their responsiveness to inflammatory cytokines both in vitro [28, 29] and in vivo [30]. It has been demonstrated that treatment of tumor bearing mice with angiogenesis inhibitors

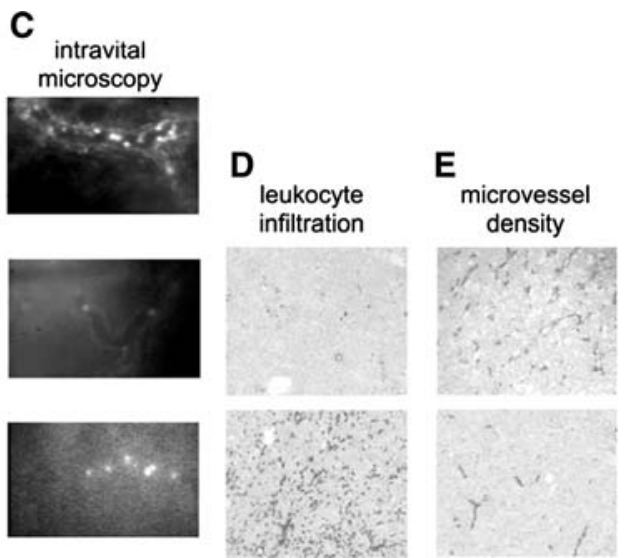

and tumor tissue after treatment with an angiogenesis inhibitor (anginex, $10 \mathrm{mg} / \mathrm{kg} / \mathrm{day}, 2$ weeks, lower panel). Video movies of these experiments can be viewed at www.angiogenesis.nl. d Leukocyte infiltration (and microvessel density. e In B16F10 melanoma tumors (upper panels) and in tumor treated with the angiogenesis inhibitor anginex (lower panels)

stimulates leukocyte infiltration into the tumor. It can be argued that it is unknown whether the leukocytes present inside a tumor-either within the tumor cell nests or in the tumor stroma - or around the tumor really contribute to the anti-tumor response or are considered only "tumor observing leukocytes". The current discussion on the benefit of leukocytes inside a tumor involves the presence of monocytes and macrophages. It has been demonstrated that the presence of these cells induces growth signals in tumor cells and stimulates angiogenesis [31, 32], leading to a worse prognosis. Current research is performed to demonstrate the contribution of angiogenesis inhibitors to this immune response. Since an enhanced number of leukocytes in or around the tumor is most often correlated to a beneficial prognosis, it is most likely that infiltration is a sign of an ongoing anti-tumor immune response.

Angiogenesis inhibition has been demonstrated to be especially of benefit in combination with other anti-cancer strategies. In early mouse studies it was already noted that angiogenesis inhibition when combined with chemotherapy has excellent anti-tumor activity [33]. Next to many explanations for synergism, one of the best explanations is the phenomenon of vessel normalization. Upon exposure to angiogenesis inhibitors blood vessels normalize from tumor induced enhanced permeabilization and tortuous morphology. This leads to normalization of the interstitial pressure which leads to enhanced sensitivity of tumor cells to chemotherapeutic agents [34]. It is therefore not unexpected that the first approval of an angiogenesis inhibitor, Avastin, was for use against colorectal cancer in combination with intravenous 5-fluorouracil-based chemotherapy. Also other anti-cancer strategies, such as radiation therapy, have 
shown to improve by angiogenesis inhibition [35]. The results as described in the current paper suggest that an immunotherapy approach against cancer should also significantly benefit from angiostasis. The development of immunotherapy strategies is currently very rapid. While until the 1980s immunotherapy was mostly treatment with recombinant cytokines (e.g., interleukin-2, interferon), after that strategies using leukocyte transfer or stem cell transplantations, and vaccination strategies using peptides and antigen loaded dendritic cells (DC) were developed. It is fundamental to any form of immunotherapy that an induced immune response leads to the generation of tumor specific leukocytes that are able to reach the tumor cells through the tumor vasculature. It is highly expected that anti-angiogenesis therapy may improve future immunotherapy regimens.

Open Access This article is distributed under the terms of the Creative Commons Attribution Noncommercial License which permits any noncommercial use, distribution, and reproduction in any medium, provided the original author(s) and source are credited.

\section{References}

1. Carmeliet P (2005) Angiogenesis in life, disease, and medicine. Nature 438:932-936

2. Griffioen AW, Molema G (2000) Angiogenesis: potentials for pharmacologic intervention in the treatment of cancer, cardiovascular diseases, and chronic inflammation. Pharmacol Rev 52:237268

3. Molema G, Griffioen AW (1998) Rocking the foundations of solid tumor growth by attacking the tumor's blood supply. Immunol Today 19:392-394

4. Folkman J (1995) Angiogenesis in cancer, vascular, rheumatoid, and other disease. Nat Med 1:27-31

5. Piali L, Fichtel A, Terpe HJ, Imhof BA, Gisler RH (1995) Endothelial vascular cell adhesion molecule 1 expression is suppressed by melanoma and carcinoma. J Exp Med 181:811-816

6. Wu NZ, Klitzman B, Dodge R, Dewhirst MW (1992) Diminished leukocyte-endothelium interaction in tumor microvessels. Cancer Res 52:4265-4268

7. Gamble JR, Vadas MA (1988) Endothelial adhesiveness for blood neutrophils is inhibited by transforming growth factor-beta. Science 242:97-99

8. Nooijen PT, Westphal JR, Eggermont AM, Schalkwijk C, Max R, de Waal RM, Ruiter DJ (1998) Endothelial P-selectin expression is reduced in advanced primary melanoma and melanoma metastasis. Am J Pathol 152:679-682

9. Griffioen AW, Damen CA, Blijham GH, Groenewegen G (1996) Tumor angiogenesis is accompanied by a decreased inflammatory response of tumor-associated endothelium. Blood 88:667-673

10. Griffioen AW, Damen CA, Martinotti S, Blijham GH, Groenewegen $G$ (1996) Endothelial intercellular adhesion molecule-1 expression is suppressed in human malignancies: the role of angiogenic factors. Cancer Res 56:1111-1117

11. Hellwig SM, Damen CA, van Adrichem NP, Blijham GH, Groenewegen G, Griffioen AW (1997) Endothelial CD34 is suppressed in human malignancies: role of angiogenic factors. Cancer Lett 120:203-211

12. Melder RJ, Koenig GC, Witwer BP, Safabakhsh N, Munn LL, Jain RK (1996) During angiogenesis, vascular endothelial growth factor, and basic fibroblast growth factor regulate natural killer cell adhesion to tumor endothelium. Nat Med 2:992-997

13. Detmar M, Brown LF, Schon MP, Elicker BM, Velasco P, Richard L, Fukumura D, Monsky W, Claffey KP, Jain RK (1998) Increased microvascular density and enhanced leukocyte rolling and adhesion in the skin of VEGF transgenic mice. J Invest Dermatol 111:1-6

14. McCourt PA, Ek B, Forsberg N, Gustafson S (1994) Intercellular adhesion molecule-1 is a cell surface receptor for hyaluronan. J Biol Chem 269:30081-30084

15. Kim I, Moon SO, Park SK, Chae SW, Koh GY (2001) Angiopoietin-1 reduces VEGF-stimulated leukocyte adhesion to endothelial cells by reducing ICAM-1, VCAM-1, and E-selectin expression. Circ Res 89:477-479

16. Guenzi E, Topolt K, Cornali E, Lubeseder-Martellato C, Jorg A, Matzen K, Zietz C, Kremmer E, Nappi F, Schwemmle M, Hohenadl C, Barillari G, Tschachler E, Monini P, Ensoli B, Sturzl M (2001) The helical domain of GBP-1 mediates the inhibition of endothelial cell proliferation by inflammatory cytokines. EMBO J 20:5568-5577

17. Guenzi E, Topolt K, Lubeseder-Martellato C, Jorg A, Naschberger E, Benelli R, Albini A, Sturzl M (2003) The guanylate binding protein-1 GTPase controls the invasive and angiogenic capability of endothelial cells through inhibition of MMP-1 expression. EMBO J 22:3772-3782

18. Hellebrekers DM, Jair KW, Vire E, Eguchi S, Hoebers NT, Fraga MF, Esteller M, Fuks F, Baylin SB, van Engeland M, Griffioen AW (2006) Angiostatic activity of DNA methyltransferase inhibitors. Mol Cancer Ther 5:467-475

19. Hellebrekers DM, Castermans K, Vire E, Dings RP, Hoebers NT, Mayo KH, Oude Egbrink MG, Molema G, Fuks F, van Engeland M, Griffioen AW (2006) Epigenetic regulation of tumor endothelial cell anergy: silencing of intercellular adhesion molecule- 1 by histone modifications. Cancer Res 66:10770-10777

20. Hellebrekers DM, Melotte V, Vire E, Langenkamp E, Molema G, Fuks F, Herman JG, Van Criekinge W, Griffioen AW, van Engeland M (2007) Identification of epigenetically silenced genes in tumor endothelial cells. Cancer Res 67:4138-4148

21. Flati V, Pastore LI, Griffioen AW, Satijn S, Toniato E, D'Alimonte I, Laglia E, Marchetti P, Gulino A, Martinotti S (2006) Endothelial cell anergy is mediated by bFGF through the sustained activation of p38-MAPK and NF-eb inhibition. Int J Immunopathol Pharmacol 19:761-773

22. Griffioen AW, Relou IA, Gallardo Torres HI, Damen CA, Martinotti S, De Graaf JC, Zwaginga JJ, Groenewegen G (1998) The angiogenic factor bFGF impairs leukocyte adhesion and rolling under flow conditions. Angiogenesis 2:235-243

23. Tromp SC, oude Egbrink MG, Dings RP, van Velzen S, Slaaf DW, Hillen HF, Tangelder GJ, Reneman RS, Griffioen AW (2000) Tumor angiogenesis factors reduce leukocyte adhesion in vivo. Int Immunol 12:671-676

24. Dirkx AE, Oude Egbrink MG, Kuijpers MJ, van der Niet ST, Heijnen VV, Bouma-ter Steege JC, Wagstaff J, Griffioen AW (2003) Tumor angiogenesis modulates leukocyte-vessel wall interactions in vivo by reducing endothelial adhesion molecule expression. Cancer Res 63:2322-2329

25. Bouma-ter Steege JC, Baeten CI, Thijssen VL, Satijn SA, Verhoeven IC, Hillen HF, Wagstaff J, Griffioen AW (2004) Angiogenic profile of breast carcinoma determines leukocyte infiltration. Clin Cancer Res 10:7171-7178

26. Baeten CI, Castermans K, Hillen HF, Griffioen AW (2006) Proliferating endothelial cells and leukocyte infiltration as prognostic markers in colorectal cancer. Clin Gastroenterol Hepatol 4:13511357

27. Zhang L, Conejo-Garcia JR, Katsaros D, Gimotty PA, Massobrio M, Regnani G, Makrigiannakis A, Gray H, Schlienger K, Liebman 
MN, Rubin SC, Coukos G (2003) Intratumoral T cells, recurrence, and survival in epithelial ovarian cancer. N Engl J Med 348:203213

28. Griffioen AW, Damen CA, Mayo KH, Barendsz-Janson AF, Martinotti S, Blijham GH, Groenewegen G (1999) Angiogenesis inhibitors overcome tumor induced endothelial cell anergy. Int $\mathrm{J}$ Cancer 80:315-319

29. Pappas NP, Hillen HF, Wagstaff J, Griffioen AW (1999) Angiogenesis and the regulation of antitumor defense. Ned Tijdschr Geneeskd 143:1555-1559

30. Dirkx AE, oude Egbrink MG, Castermans K, van der Schaft DW, Thijssen VL, Dings RP, Kwee L, Mayo KH, Wagstaff J, Bouma-ter Steege JC, Griffioen AW (2006) Anti-angiogenesis therapy can overcome endothelial cell anergy and promote leukocyte-endothelium interactions and infiltration in tumors. FASEB J 20:621-630

31. Dirkx AE, Oude Egbrink MG, Wagstaff J, Griffioen AW (2006) Monocyte/macrophage infiltration in tumors: modulators of angiogenesis. J Leukoc Biol 80:1183-1196
32. Leek RD, Lewis CE, Whitehouse R, Greenall M, Clarke J, Harris AL (1996) Association of macrophage infiltration with angiogenesis and prognosis in invasive breast carcinoma. Cancer Res 56:46254629

33. Teicher BA, Holden SA, Ara G, Korbut T, Menon K (1996) Comparison of several antiangiogenic regimens alone and with cytotoxic therapies in the Lewis lung carcinoma. Cancer Chemother Pharmacol 38:169-177

34. Tong RT, Boucher Y, Kozin SV, Winkler F, Hicklin DJ, Jain RK (2004) Vascular normalization by vascular endothelial growth factor receptor 2 blockade induces a pressure gradient across the vasculature and improves drug penetration in tumors. Cancer Res 64:3731-3736

35. Dings RP, Loren M, Heun H, McNiel E, Griffioen AW, Mayo KH, Griffin RJ (2007) Scheduling of radiation with angiogenesis inhibitors anginex and Avastin improves therapeutic outcome via vessel normalization. Clin Cancer Res 13:3395-3402 